\title{
INTRODUCING BUSINESS EDUCATION IN EARLY MIDDLE SCHOOL - MATH PERSPECTIVE
}

\author{
Borislav Lazarov \\ Institute of Mathematics and Informatics, BAS, Sofia, Bulgaria \\ Daniella Severinova \\ Wonder Group, Sofia, Bulgaria
}

CMESTE

JEL Category: A21, 121

\begin{abstract}
This paper presents briefly the authors' experience in stating educational goals, developing didactics and organizing elements of early business education. St. George Private Secondary School, Sofia, Bulgaria, educates mainly students who are potential managers and leaders in various areas of the industry and social life. The school plan for the $8^{\text {th }}$ grade contains a course in management where the concepts of business are introduced from a qualitative and descriptive perspective. However, there are a lot of topics related to business education in mathematics curricula for the $6^{\text {th }}$ and $7^{\text {th }}$ grade. The methods we apply are of three types: problem solving as a manager activity, project design from the perspective of business practice, and giving idea about optimization. The problem-solving approach allows students to operationalise some concepts via putting business strategies into practice. We modified the Polya's 4-step problem-solving plan to a 5-point check-list which could serve as a general management strategy. In order to help students to learn in meaningful ways we incorporate projectoriented initiatives connected with the relevance of an interest-based curriculum. Parallel to the particular subject objectives the project-oriented initiatives provide opportunities for multipurpose integrated consideration of topics. The integrated approach we apply encourages the future managers to take decisions in various situations: content interpretation, implementation of IT, layout design, etc. Any project-oriented initiative is planned to form a kind of knowledge and skills that synthesize the analytical knowledge and skills developed in particular subjects. Central role in this practice plays the mathematics teaching-learning process performed in Socratic style. The incorporation of new teaching methods has been done with respect to the TRIZ theory.
\end{abstract}

Keywords: business education, project-oriented education, synthetic competenc, TRIZ, Socratic style

\section{INTRODUCTION}

The target group of St. George Private Secondary School, Sofia, Bulgaria, is mainly of students who

Address of the author:

Borislav Lazarov

麦=l lazarov@math.bas.bg are potential managers and leaders in various areas of the industry and social life. The building of common knowledge and skills of such students 
is expected to take into account the profile of the target group. The school plan for the 8 th grade contains a course in management where the concepts of business are introduced from qualitative and descriptive perspective (Jones, 2011). However, there are a lot of topics related to business education in both mathematics curricula for $6^{\text {th }}$ and $7^{\text {th }}$ grade: the mandatory (according to the Bulgarian secondary school standards) and the facultative (with respect to the National Curriculum for England and Wales). This dichotomy allows to reconsider a lot of math activities from different view points and to meet some specifics of the target group. First, we apply problem-solving method that allows students to operationalize some math concepts via putting in practice strategies which have interpretation as business routine. Second, we designed an interest-based curriculum to incorporate projectoriented initiatives. This approach provides additional opportunities for students to learn some theoretical topics in meaningful way from manager's perspective.

\section{THEORETICAL FRAMEWORK}

Recognizing the importance of individual support of students in a matter like business education, we designed our own theoretical model based on the so called Didactical Model Taipei (Lazarov, 2013). Central role in this model plays the modern Socratic style of teaching. The Didactical Model Taipei aims to serve the gifted education, but it was modified for education of students with average abilities in mathematics. Crucial component of the model is the structure of the local behavioral environment. In our opinion the integrated approach, realized via project-oriented initiatives, is the school strategy, which assures proper local behavioral environment.

Another important component of the model is the assessment style. We prefer fuzzy achievement scale when evaluating the outcomes which allows us to state indicators for positive evaluation of students' projects: we assess the progress in any direction instead of highlighting the students' gaps in knowledge or their incomplete coverage of the standards. The interventions we make to correct students' learning are mostly indirect - by giving some good examples of other teams or individuals as well as some potentially helpful ways to improve their work. Often the control on the students' project work is left to the students themselves and the teacher's role is just to moderate a discussion.

Parallel to the particular subject objectives, the project-oriented initiatives provide opportunities for multipurpose integrated consideration of topics. The integrated approach we apply encourages the future managers to make decisions in various situations: content interpretation, implementation of IT, layout design, etc. Any project-oriented initiative is planned to form some kinds of knowledge and skills that synthesize the analytical knowledge and skills built in some particular subjects (Lazarov \& Severinova, 2014). After building and proving it in reproductive tasks, the creative work of teams and individuals is appreciated.

The antinomies we met while putting the theory into practice were partially solved by us applying the TRIZ (or Altshuller's) method (ibid.).

\section{PROBLEM SOLVING AS A MANAGER ACTIVITY}

G. Polya stated 4 steps in solving a math problem which became classic in math education because of their universal implementation (Polya, 1961). However, a lot of variations of these steps were created to meet the specifics of different particular educational programs.

We reconsider the problem-solving in mathematics stating additional goal: building initial skills in managing challenges. Our modification of the Polya's model is a Five-pointchecklist (FPC) that serves the stated goal a little bit better: Question; Resources; Plan; Execution; Evaluation. The methodology we apply is

- students start with the simplest reproductive problems to elaborate the steps of the FPC;

- they are encouraged to apply it to various similar situations;

- students are consulted in Socratic style interaction whenever it is necessary which corresponds to the tutoring model (Lazarov, 2013);

- some comments about the implementation of the strategy highlight its importance in business decision making.

Below we are going to describe the steps of the FPC in general and an example of how it works we give in Appendix 1. 


\subsection{Question}

Understanding the task to be solved means some (intuitive) connections to be established between the desired outcome and the data given via available technological status quo. Bulgarian math textbooks contain a lot of problems about manufacturing goods. Our teaching style is to present them from actor-oriented perspective.

\subsection{Resources}

Usually this point is restricted to clarification of data types in the problem, We extend the meaning of resources by adding students' situative know-how (e.g. their knowledge and skills), including general rules (e.g. synchronization of measuring units), mathematical methods (e.g. formula, algorithms) and tools (e.g. map, grid, ruler, compass).

\subsection{Plan}

This step is related to modeling the situation described in the problem taking into account the available resources. The expected outcome here is a mathematical step-by-step procedure to be designed or composing equations to be solved.

\subsection{Execution}

Putting the plan into practice and getting a solution or just an answer is usually pure mathematical activity.

\subsection{Evaluation}

This is perhaps the most important step from business-education perspective. Usually the solution of a math problem ends with a check of the answer. We appreciate this part of the solution but in addition we require a kind of justification of the outcomes, i.e. whether the mathematical results are coherent with the real situation described in the problem. Sometimes the step Execution is skipped in certain problems when some adequate reasoning is made.

\subsection{Summary of Section 3}

As it was mentioned in the introduction, the $8^{\text {th }}$ grade business course presents a large number of manager's activities from qualitative and descriptive side (Jones, 2011). The quantitative problems give another view point, namely how the numbers in diagrams and graphics come from different real life situations. In our opinion such preparatory work in $6^{\text {th }}$ and $7^{\text {th }}$ grade allows better operationalization of the concepts related to the market and industry that appear in higher grades.

\section{PROJECT DESIGN FROM THE PERSPECTIVE OF BUSINESS PRACTICE}

The complexity of manager's practice requires estimation of the impact of many parameters. The subject education in middle school presents the big picture of our life in a fragmentary analytical way. This style leads away from the expected competence that our students should have at the end of their education at St. George School. So we adopt an integrated approach in teaching, which aims to form knowledge and skills of synthetic type.

As an important component of our integrated approach we state the goal to build initial skills in organizing and presenting different types of knowledge related to data manipulation.

The problems from the textbooks alone do not provide enough space for realization of this goal, but the project-oriented education does, and we organize auxiliary education in such mode parallel to the main stream of the compulsory curriculum. Data interpretation is crucial for everyday business practice. Some of the POIs we recently put into practice are focused on making the students interpret correctly graphically presented data but also to elaborate abilities in graphical representation of digital data. Below we are going to present two project-oriented initiatives (POIs), which are focused on data manipulation.

\subsection{POI Movement and Change}

Bulgarian $6^{\text {th }}$ grade compulsory curricula in science and mathematics provide rare opportunities for integration of topics related to change and movement, on one hand, and the types of writing large or tiny numbers as well as digital partitions or distributions, on the other hand. We catch this opportunity to orchestrate the POI titled Movement and Change. 


\subsubsection{Project parameters}

Our $6^{\text {th }}$ graders were invited to describe in quantitative way a phenomenon related to science education (physics, biology, chemistry, astronomy). The project assignment included: finding reliable sources about the phenomenon;

\section{DEVELOPMENT}

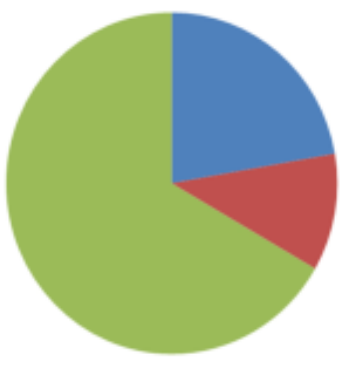

- PREGNANCY

- YOUTH

" MATURE extracting the related digital information; visualizing this information through diagram; comparing and evaluating the changes. Students were divided into small teams of 2 or 3 persons. The teams distributed the tasks and responsibilities by themselves.

\section{MATURITY}

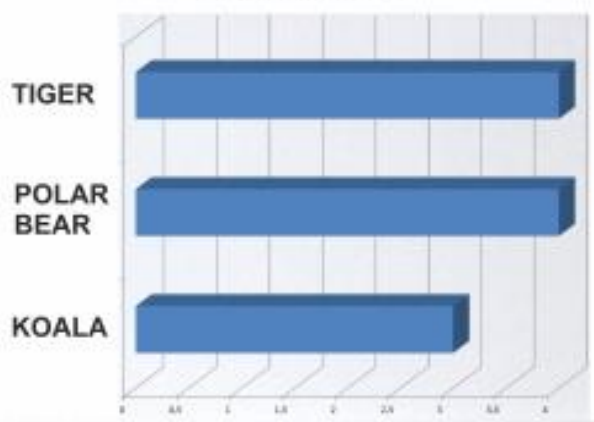

Fig. 1 Phases of life of tiger $(L)$ and comparison of average life pregnancy of tiger, polar bear and koala from a students' project $(R)$

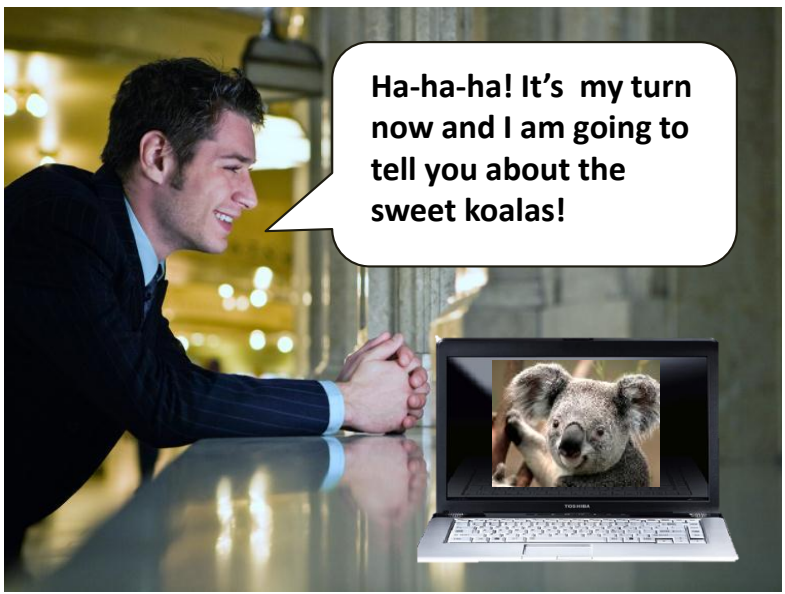

Fig. 2 Presentation style: each animal is i

\subsubsection{Two examples}

There was a variety of topics presented by the students: speed of vehicles, diffusion, stages of mammals' development, etc.

A students' project about the stages of mammals' development (not titled) represents the three phases of mammals' life: embryonic, infant and mature. Students were focused on three species: tiger, polar bear and koala (Figure 1). ${ }^{1}$

The team presented the facts from imaginary manager perspective (Figure 2). The insinuation was that the wild-life protection could be viewed

${ }^{1}$ All figures in the paper are taken from students، projects. Following the editor's recommendations the

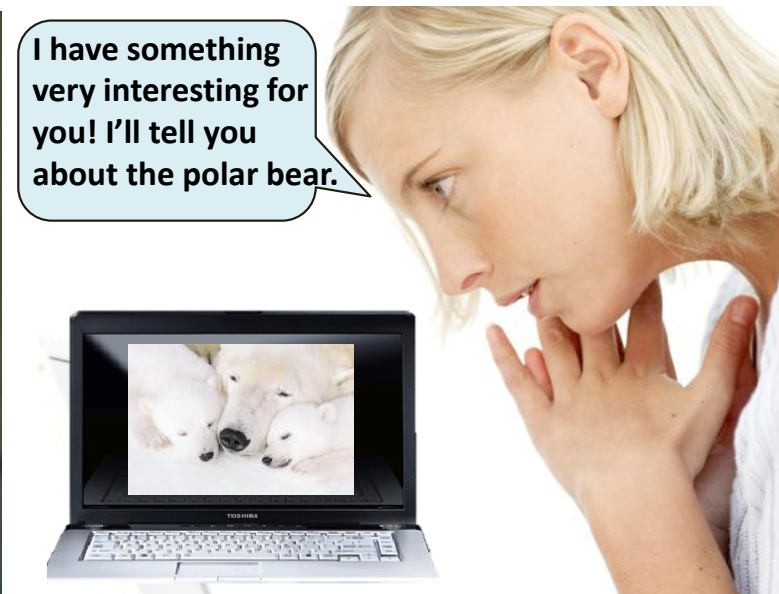

as a kind of management and they are considered about these particular species.

Students demonstrated skills in manipulation and interpretation of digital data which were presented in different modes. They used electronic tables, as well as pie and chart diagrams to visualize the data.

Another emblematic students' project was entitled Diffusion.

The team compared the diffusion speed of atoms or molecules in bimetal coins, liquid solutions, fragrances and during explosion (Figure3).

text in Figures 1-4 and 6 is edited and translated from Bulgarian by the authors of the article. 


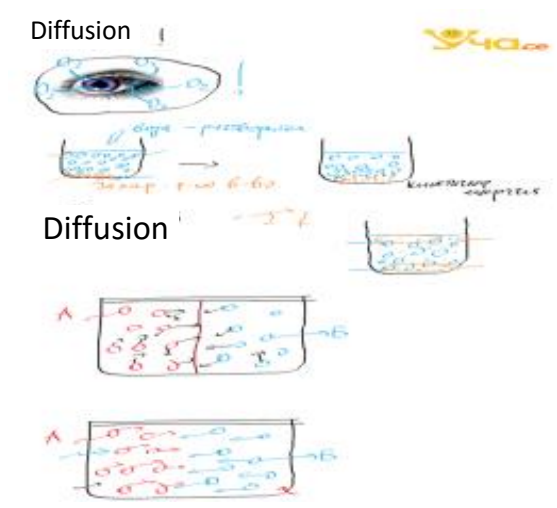

\section{A BIT OF MATHEMATICS}

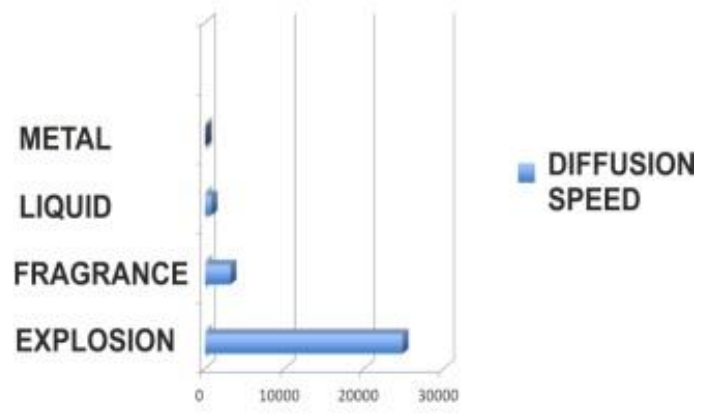

Fig.3. Illustration of the phenomenon (L) and comparison of diffusion speed of 4 processes $(R)$

Students captured the data from different sources. After gathering the information they unified the measures and wrote the numbers in standard mode to compare them. The qualitative evaluation was done not by the magnitudes but by their powers. We encourage such style and consider it closer to the business practice of evaluation and estimation of quantitative data.

\subsubsection{An important detail}

Students demonstrated considerable culture in presenting the projects. But a very important detail we would like to stress was the correct use of data sources. In the not-titled-project the team cited 4 printed books and in the project Diffusion there were references to 9 websites. We consider such attitude a crucial feature of a responsible manager.

\subsection{POI Diets}

The POI about the diets required higher level of data manipulation because any diet is related to several factors. On one hand, there are the food ingredients: calories, proteins-fats-carbohydrates content, minerals, vitamins; on the other hand, there are the food sources: grain, meat, fruits and vegetables. Some teams composed in their projects daily feeding program: breakfast, lunch and dinner. In fact, our $6^{\text {th }}$ graders solved a real managerial task: to study the state of the matter and to propose a 'business plan' for feeding specific groups of people, like pregnant women (Figure 4) or babies.

\section{DAILY FOOD}

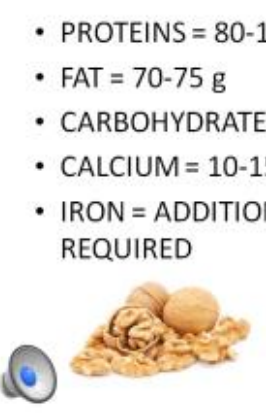

\section{-100 g}

- $\mathrm{FAT}=70-75 \mathrm{~g}$

- CARBOHYDRATE $=100 \mathrm{~g}$

- CALCIUM $=10-15 \mathrm{~g}$

- IRON = ADDITIONAL NOURISHMENT REQUIRED

Fig. 4. The digital data and the illustration from the students project Diet during expectancy

The teams' presentation skills were above our expectations. Students demonstrated not only knowledge, skills and attitude but also confidence and style.

\section{GETTING IDEA ABOUT OPTIMIZATION}

Our impression is that scientific methods are not highly appreciated in Bulgarian business circles. However, the successful business practice, 
especially of large companies, requires optimizations of different processes which lead to application of mathematical methods. This is why we decided to organize a POI called Top Profit to show our students how mathematics works in making money.

\subsection{Background and goals}

The $7^{\text {th }}$ grade math-in-English curriculum at St. George School includes simultaneous linear equations and an introductory lesson about linear optimization. Another reason to go deeper in the matter is the potential application of simultaneous equation in the examination test at the end of the $7^{\text {th }}$ grade. Hence, the educational goal we stated was manifold, but here we will focus on the business educational component, which is: to highlight some benefits of the application of mathematical and scientific methods in business practice.

\subsection{Project assignment and results}

The project assignment was as follows:

- three given problems to be solved in paperand-pencil mode,

- another problem of the same type to be composed and solved,

- a computer presentation to be designed and performed.

The first two problems were replicas of the ones from the textbook (Pledger, 2009); the third one was taken (directly or slightly modified for different project assignments) from a university math course (Jagdish \& Lardner, 1989). The project assignment is given in Appendix 2.

The outcomes of the project work were very satisfactory - the teams demonstrate knowledge and skills in both graphical and analytical method, they prepared accurate diagrams and drawings, their presentation files were properly designed. Students used shorthand as thick and cross to avoid long explanations in their paper-and-pencil part of the project.

Most of the students showed considerable level of reasoning and interpretation of the solutions (Figure 5). The teams gave sensible explanations even when marginal cases appeared in the $4^{\text {th }}$ problem (because the problem data was not well adjusted - the students chose figures from common sense perspective).

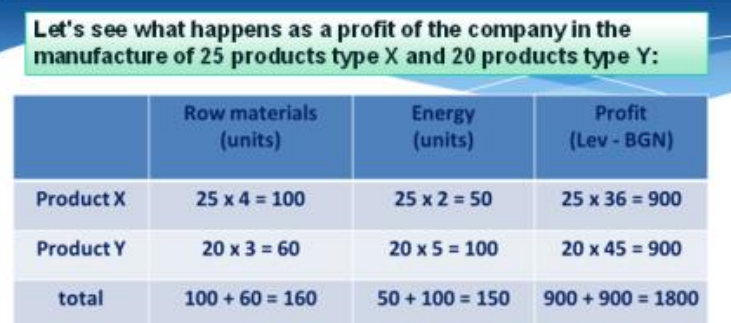

So, in the manufacture of 25 products type $X$ and 20 products type $Y$ the company will use completely all units of raw materials and energy and maximize profits from 1800 lev.

Fig. 5. Reasoning the "Top" of the profit

During the pilot experiment we observed that the lack of skills in performing algebraic transformations was a serious obstacle for some students. So we decided to overcome this problem by organizing a short training in dynamic geometry software instead of organizing extra math drills (Figure 6). The effect was a significant growth of the students' interest to mathematical methods. Later we applied the graphical method of solving simultaneous equations to solve several problems like the ones in the graduating test after $7^{\text {th }}$ grade. The GeoGebra solution of such problems was a big surprise for the students but also a clear message that any math knowledge could have a lot of useful applications.

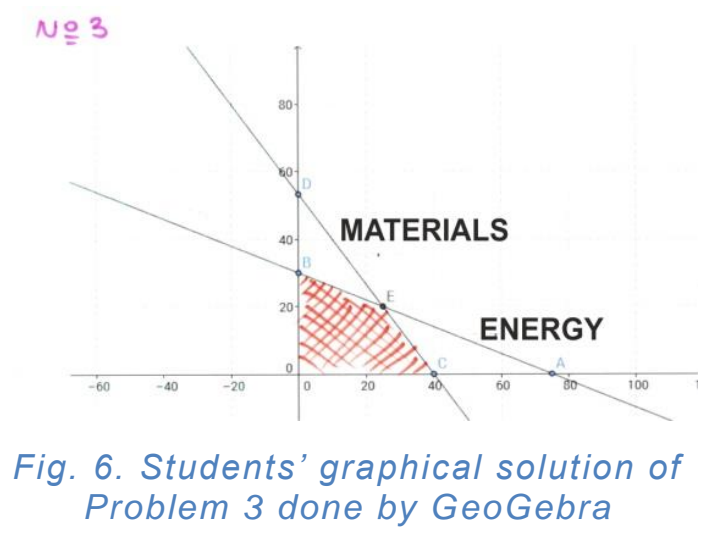

\section{Closing remarks}

The business course (Jones, 2011) is full of charts, graphics and tables, which represents in a qualitative mode different quantitative characteristics of trade, manufacturing etc. But there are little or none explanations of the origin of these diagrams. Such style could be misleading that the business and management are something mysterious or supernatural. 
Our approach is rather different - we are trying to explain students that any responsible business decision needs serious preparatory work. Proper orientation in a complex business environment could be successfully supported by scientific methods.

The math education is the natural place for the quantitative description of some business phenomena before starting special business courses. Our practice clearly shows that accommodation of business examples in mathematics education returns dividends to the math education itself. A lot of math concepts and methods make more sense immersing them in a virtual business environment, especially for our students. We consider project-oriented initiatives as an extension of classroom practice. The examples we gave above clearly show that POIs provide much more opportunities for introducing elements of business education on such an early stage like $6^{\text {th }}$ and $7^{\text {th }}$ grade.

Finally we should note that the incorporation of our experimental teaching in regular school practice was done according to the Altschuller's methodology (known also as TRIZ theory) (Lazarov \& Severinova, 2014). Altschuller's principles are very helpful any time some antinomies rise. Let us give two examples about the types of antinomies we met.

First example. As a rule the main part of a project initiative is separate in additional facultative classes where no official marks are provided. Thus a motivation factor for the students was the impact of their performance in the POIs on the marks in regular math classes. Such approach requires synchronization of the indicators for progress in $\mathrm{POI}$ with official educational standards. But stating strict benchmarks for the indicators contradicts the ideology to evaluate any progress and to neglect the gaps. Here the Altshuller's Principle 3. Local quality helps saying: 'make each part of an object or system function in conditions most suitable for its operation' (Altschuller, 1964). We apply this principle in the following manner: in any particular student's project we search for some parts that are better than the similar parts in other projects and highlight these parts in a comparative evaluation.

Second example. The application of dynamic geometry software for solving simultaneous equations requires some changes in the school plan. Some activities like introduction of the interface of the GeoGebra were transferred to the IT classes. All these requires forming teams of teachers, organizing control etc. However, some activities in math and IT classes complete each other and the Altshuller's Principle 5. Merging suggests: bring closer together (or merge) identical or similar objects or systems ; assemble identical or similar parts to perform parallel operations (ibid.). We apply this principle by organizing lessons of mixed type - teaching the GeoGebra interface in math classes and performing drills during IT classes on math examples.

We finish this article by quoting Dunaway-Petty's view point that business education curriculum should be part of a larger system, which comprises a variety of teaching and learning contexts (Dunaway-Petty, 2013). In our opinion the existing contexts in math education could be a relevant part of such system.

\section{ACKNOWLEDGMENTS}

Authors thank to Tsvetanka Doganova and Diana Semkova for the cooperation in bringing to live the POls described in sections 4 and 5 .

\section{WORKS CITED}

Al'tshuller G. (1969). Algoritm izobreteniya. Moskovskiy rabochiy . Moskva .English translation: Altshuller, G. The Innovation Algorithm (TRIZ, systematic innovation and technical creativity). Worcester, Massachusetts. 1999.

Dunaway-Petty, K. (2013). Effective methods of teaching business education. http://www.slideshare.net/pettyk07/effective-methods-of-teaching-business-education

Jagdish, A., \& Lardner, R. (1989). Mathematical analysis. Prentice-Hall, New Jersey. pp 401-404.

Jones, R. (2011) Edexcel International GCSE Business Studies. Pearson.

Lazarov, B. (2013). Application of some cybernetic models in building individual educational trajectory. Information Models and Analyses. 2(1), 90-99. 
Lazarov, B., \&, Severinova, D. (2014, 07 15). Incorporating integrated approach in secondary school. (Z. Čekerevac, Ed.) MEST Journal, 2(2), 113-120. Doi:10.12709/mest.02.02.02.12

Polya, G. (1961) Kak reshatj zadachu (How to solve it). (Russian translation) UCHPEDGIZ, 1961, pp 40-43.

Pledger, K. (editor). (2009) 6-8 Level Up Maths. Heinemann, Essex, pp 26-27.

\section{APPENDIX 1}

The textbook Mathematics for $7^{\text {th }}$ grade by Lozanov et al. contains several lessons about modeling with linear equations (Anubis, Sofia, 2008, pp 100-116. In Bulgarian). The topic is presented in several lessons about movement, work, alloy and finances, separately for any one of the listed themes (similar is the situation with the other Bulgarian math textbooks for $7^{\text {th }}$ grade). We do not accept such approach because it stands outside the big idea of mathematics to describe different phenomena in a universal mode. Our idea is quite different: to show students how a mathematical model works in different problems and to propose them a general scheme (FPC) for solving such problems (Lazarov \& Georgieva, 2001. Zadachi i testove po matematika (in English 'Math problems and tests'). Trud, Sofia, pp 100-126). Here we are going to give an idea about our teaching style through application of the distance-velocity-time equation.

The next three examples are given to the students to be worked out consecutively in a lesson. They are offered to follow the five-point-checklist in their solutions.

Example 1. According to the schedule of a shuttle bus, the distance between $A$ and $B$ is to be traveled with average speed of $60 \mathrm{~km} / \mathrm{h}$. If the bus departs from $A$ and runs this distance with average speed of $70 \mathrm{~km} / \mathrm{h}$, then one hour before the scheduled time of arrival it will be $30 \mathrm{~km}$ apart from B. Find the distance between A and B.

Example 2. Mr. Ygreksen must repay a loan in monthly payment of $\$ 40$ but he decided to repay the loan in $\$ 45$ per month. This is why one month before the deadline only $\$ 20$ remained to be paid. Find the total amount of Mr. Ygreksen's loan.

Example 3. A farmer planed to sow a field by sowing 73 dka daily. He managed to sow $14 \mathrm{dka}$ more every day. As a result, two days before the planned time just $6 \mathrm{dka}$ remained to be sown. Find the area of the field.

\section{Solution of Example 1.}

Step 1 (Question). Find the distance $s=A B$ by comparing two movements.

Step 2 (Resources). The equation $s=v \cdot t$ and velocity $v_{1}=60$ and $v_{2}=70$ data from the statement. Implicit resource: students have in their arsenal also the method of solving simple simultaneous equations by eliminating one of the variables. There is one more resource available after the lesson about the graphical method of solving simultaneous equations performed in GeoGebra.

Step 3 (Plan). Denote by $t$ the scheduled travelling time in hours. We are going to express $s$ in the two movements.

Movement 1: $s=v_{1} \cdot t=60 t$.

Movement 2: $s=v_{2} \cdot(t-1)+30=70(t-1)+30$.

Since we have more information about $t$, the plan is to find first $t$ and then $s$.

Step 4 (Execution). We can write and solve an equation about $t$ :

$$
60 t=s=70(t-1)+30 \rightarrow 60 t=70 t-40 \rightarrow-10 t=-40 \rightarrow t=4 \rightarrow s=60 \cdot 4=240 .
$$

Step 5 (Evaluation). The result seems plausible because $240 \mathrm{~km}$ is a common distance between two towns in Bulgaria. Check: $70 \cdot(4-1)+30=240-$ the result is coherent with the second movement too. 
Comment. It is clear that the solutions of Examples 2 and 3 repeat the solution of Example 1. The students are encouraged to state by themselves another problems which could be solved applying the same model, e.g. to find the volume of a reservoir that is filled twice from a pipe: the firs time in one flow rate and the second time in another flow rate. The lesson includes also a discussion about the role of a manager in: 1) identifying the problem in a real-life situation, 2) clarifying the available resources, 3) designing a plan for solving the problem, 4) organizing the execution of the plan, and 5) evaluating the outcomes of the execution.

\section{APPENDIX 2}

The project assignment for the POI Top Profit

Problem 1. A company manufactures two phone models: $X$ and $Y$. It takes 4 hours to produce each item of type $X$ and the company makes profit of 5 levs (Lev is the Bulgarian currency) from such an item; it takes 5 hours to produce each item of type $Y$ and the company makes profit of 11 levs from it. The company can produce at most 300 phones of each type and has 1600 hours to complete the order. Find the number of phones of each type that should be produced to get the largest profit.

Problem 2. A company manufactures two bicycle gears: $X$ and $Y$. It takes 4 hours to produce a gear $X$ and the company makes profit of 7 levs from it; it takes 2 hours to produce a gear $Y$ which makes profit of 3 levs. The company can produce at most $400 \mathrm{X}$ gears and $300 \mathrm{Y}$ gears; it has 2000 hours to complete the order. Form four equations as follows: about the maximum number of hours; about the maximum number of each gear type; about the profit. Plot the graph of the first three equations. Find the point that gives the largest profit.

Problem 3. A company manufactures two products: $X$ and $Y$. Each item of type $X$ needs 5 units of raw materials and 2 units of energy; each item of type $Y$ needs 3 units of raw materials and 4 units of energy. The company has 105 units of raw materials and 70 units of energy. It can make a profit of 200 levs from each item $X$ and 160 levs from each $Y$. Find the number of items of each type that should be produced to get the largest profit.

Problem 4. (To be designed and solved by the teams.) Below is the genuine problem of a team:

A company produces two products: $\mathrm{K}$ and $\mathrm{T}$. For producing one $\mathrm{K}$ product are used 10 ones of raw materials and 6 ones of energy; to produce on product $T$ are used 4 ones of raw materials and 8 ones of energy. The profit of one product $\mathrm{K}$ is $100 \mathrm{BGN}$ and for one $\mathrm{T}$ is $80 \mathrm{BGN}$. The company has 410 ones of raw materials and 140 ones of energy.

What amount of each product could be produced to find the largest profit?

What is that profit?

Received for publication: $\quad$ 08.07.2015

Revision received: $\quad 21.08 .2015$

Accepted for publication: $\quad 06.10 .2015$

\section{How to cite this article?}

Style - APA Sixth Edition:

Lazarov, B., \& Severinova, D. (2016, January 15). Introducing business education in early middle school - math perspective. (Z. Cekerevac, Ed.) MEST Journal, 4(1), 65-74.

doi:10.12709/mest.04.04.01.07 
Style - Chicago Sixteenth Edition:

Lazarov, Borislav, and Daniella Severinova. 2016. "Introducing business education in early middle school - math perspective." Edited by Zoran Cekerevac. MEST Journal (MESTE) 4 (1): 65-74. doi:10.12709/mest.04.04.01.07.

Style - GOST Name Sort:

Lazarov Borislav and Severinova Daniella Introducing business education in early middle school math perspective [Journal] // MEST Journal / ed. Cekerevac Zoran. - Belgrade-Toronto : MESTE, January 15, 2016. - 1 : Vol. 4. - pp. 65-74.

Style - Harvard Anglia:

Lazarov, B. \& Severinova, D., 2016. Introducing business education in early middle school - math perspective. MEST Journal, 15 January, 4(1), pp. 65-74.

Style - ISO 690 Numerical Reference:

Introducing business education in early middle school - math perspective. Lazarov, Borislav and Severinova, Daniella. [ed.] Zoran Cekerevac. 1, Belgrade-Toronto : MESTE, January 15, 2016, MEST Journal, Vol. 4, pp. 65-74. 